\title{
Avaliação nutricional da silagem de grãos úmidos de milho com diferentes teores de óleo para leitões na fase de creche
}

[Nutritional evaluation of high moisture corn silage with different oil contents for piglets in nursery phase]

\author{
C.A. Tofoli ${ }^{1}$, D.A. Berto ${ }^{2}$, M.L.P. Tse ${ }^{1}$, F.S. Wechsler ${ }^{2}$, A.M.R. Silva ${ }^{3,5}$, M.A. Trindade Neto ${ }^{4}$ \\ ${ }^{1}$ Aluno de pós-graduação - FMVZ- UNESP - Botucatu, SP \\ ${ }^{2}$ Faculdade de MedicinaVeterinária e Zootecnia - UNESP \\ Caixa. Postal 560 \\ 18618-000 - Botucatu, SP \\ ${ }^{3}$ Aluno de graduação - FMVZ-UNESP - Botucatu, SP \\ ${ }^{4}$ Faculdade de Medicina Veterinária e Zootecnia - USP - Pirassununga, SP \\ ${ }^{5}$ Bolsista da FAPESP
}

\begin{abstract}
RESUMO
Utilizaram-se 60 leitões mestiços (Large White x Landrace), desmamados com peso inicial médio de $7,9 \mathrm{~kg}$, no experimento de desempenho e 20 leitões mestiços, com peso inicial médio de $16,8 \mathrm{~kg}$, no experimento de digestibilidade para avaliar a silagem de grãos úmidos de milho com diferentes teores de óleo. O delineamento experimental foi o de blocos ao acaso em ambos os experimentos avaliou-se o valor nutricional das silagens e dos milhos secos com teor normal (4,3\%EE na MS) ou elevado de óleo (5,66\%EE na MS). Não houve efeito dos tratamentos sobre o consumo diário de ração e no ganho de peso diário nos períodos de 0 a 9 e 0 a 31 dias. Os leitões apresentaram melhor conversão alimentar em ambos os períodos estudados, quando receberam silagem e no período de 0 a 9 dias, quando foram alimentados com milho com teor mais alto de óleo. As frações digestível e metabolizável da energia foram influenciadas pelo processamento, sendo que a ensilagem proporcionou melhor aproveitamento da energia, independentemente do teor de óleo presente nos grãos.
\end{abstract}

Palavras-chave: suíno, silagem, desempenho, digestibilidade, teor de óleo

\begin{abstract}
Sixty crossbred weaned pigs (Large White $x$ Landrace) average initial body weight of $7.9 \mathrm{~kg}$ and 20 crossbred pigs average initial body weight of $16.8 \mathrm{~kg}$ were used in the performance and digestibility experiments, respectively, to evaluate high-moisture corn silage with different oil contents. The nutritional value of high-moisture corn silage and dry corn with normal (4.3\% EE in DM) or higher (5.66\% EE in DM) oil contents were analyzed. The treatments had no effect on either average daily feed intake (ADFI) or average daily gain (ADG) from 0 to 9 and 0 to 31 days. The piglets had higher feed/weight gain in both periods when fed silage and in the period from 0 to 9 days when fed higher oil content corn. In the digestibility experiment only the digestible and metabolizable fractions of energy were affected by the processing method and the silage provided higher energy utilization regardless of the oil content in the grains.
\end{abstract}

Keywords: piglet, silage, performance, digestibility, oil content

Recebido em 19 de outubro de 2004

Aceito em 3 de julho de 2006

E-mail: ctofoli@gmail.com

Apoio: FUNDUESP 


\section{INTRODUÇÃO}

O aumento da produção comercial de aves e suínos nos últimos anos impulsionou ainda mais o crescimento da cultura do milho que chega a participar em até $75 \%$ da composição total das rações. Este fato é decorrente de seu alto valor energético, principalmente devido ao elevado teor de amido, que representa cerca de $70 \%$ do peso dos grãos.

Em função da alta participação do milho no custo de produção, constantes pesquisas têm sido realizadas no intuito de encontrar alternativas mais econômicas para alimentação dos animais.

A silagem de grãos úmidos de milho é uma opção que vem sendo apresentada aos suinocultores. $\mathrm{O}$ emprego da técnica da ensilagem reduz os problemas e perdas verificadas nos períodos pré e pós-colheita, além de diminuir o período de ocupação da terra.

A silagem de grãos úmidos de milho foi introduzida no Brasil em 1981, sendo inicialmente utilizada na alimentação de suínos e, mais tarde, na alimentação de bovinos leiteiros e de corte. Entretanto, os primeiros trabalhos de pesquisa conduzidos com suínos datam do início de 1998 (Lopes et al., 2001a,b), quando foi possível comprovar o seu grande potencial na alimentação de leitões e suínos em crescimento e terminação.

A utilização da silagem de grãos úmidos de milho na dieta de suínos em terminação proporcionou melhora no ganho de peso dos animais (6,5\%), comparada com o milho seco (Duduk, 1988). Quanto à digestibilidade, a silagem de grãos úmidos apresenta maior valor nutricional que o milho seco, em decorrência da melhor utilização da fração protéica do grão (Duduk, 1988).

Paralelamente à introdução de novas técnicas no processamento dos alimentos, o melhoramento genético vegetal vem sendo amplamente explorado na intenção de produzir variedades de milho mais econômicas e eficientes, aumentando o rendimento e os níveis de produção, bem como melhorando seu valor nutritivo (Silva, 1997).

Spurlock et al. (1997) observaram que o fornecimento de milho alto-óleo para leitões em crescimento $(23 \mathrm{~kg})$ proporcionou uma melhora na eficiência alimentar de 5\% em relação ao milho convencional, sugerindo que as formulações com esta variedade podem oferecer algumas vantagens econômicas em decorrência da melhora da eficiência produtiva. Resultados semelhantes foram encontrados por Bowers et al. (2000) que verificaram melhora de $8,4 \%$ na conversão alimentar de animais em crescimento e terminação.

$\mathrm{O}$ presente experimento foi realizado com o objetivo de avaliar os efeitos da silagem de grãos úmidos de milho com diferentes teores de óleo sobre o desempenho e digestibilidade em leitões em fase de creche.

\section{MATERIAL E MÉTODOS}

O experimento de desempenho foi realizado com 60 leitões mestiços (Large White X Landrace), com peso inicial médio de 7,9kg, alojados em baias metálicas suspensas de creche, durante todo o período experimental (33 a 64 dias de idade).

O delineamento experimental foi o de blocos ao acaso com arranjo fatorial $2 \times 2$ ( 2 teores de óleo $\times 2$ métodos de conservação) e cinco repetições com três leitões por parcela. Os critérios adotados para a formação dos blocos foram o peso, o sexo e parentesco da leitegada. Os tratamentos foram: $\mathrm{T} 1=$ rações à base de grãos secos de milho, com teor normal de óleo; $\mathrm{T} 2=$ rações à base de silagem de grãos úmidos de milho com teor normal de óleo; $\mathrm{T} 3=$ rações à base de grãos secos de milho, com teor elevado de óleo; T4= rações à base de silagem de grãos úmidos de milho com teor elevado de óleo. $\mathrm{O}$ milho seco e as silagens equivalentes eram de um mesmo híbrido, ambos classificados como de textura dura, e os valores de extrato etéreo no milho normal e no milho com teor elevado de óleo foram de $4,3 \%$ e $5,7 \%$ na matéria seca, respectivamente.

Durante o período experimental (31 dias) foram fornecidas três rações à vontade, sendo ração pré-inicial nos primeiros nove dias, ração inicial I do $10^{\circ}$ ao $25^{\circ}$ dia e ração inicial II, do $26^{\circ}$ ao $31^{\circ}$ dia (Tab. 1). As rações foram formuladas para atender, no mínimo, as exigências nutricionais propostas pelo Nutrient... (1998), 
exceto para proteína bruta, para cada uma das fases estudadas. Os teores de matéria seca das silagens foram corrigidos para o mesmo valor de matéria seca do milho seco, e foram utilizados fatores de correção para substituição total do milho seco pelas silagens nas rações.

Tabela 1. Composição percentual e valores calculados das rações fornecidas aos leitões durante o período de creche ${ }^{1}$

\begin{tabular}{|c|c|c|c|}
\hline & $\begin{array}{c}\text { Fase I (1-9 dias) } \\
\%\end{array}$ & $\begin{array}{c}\text { Fase II (10-25 dias) } \\
\%\end{array}$ & $\begin{array}{c}\text { Fase III (26-31 dias) } \\
\%\end{array}$ \\
\hline \multicolumn{4}{|l|}{ Ingrediente } \\
\hline Milho moído & 35,000 & 52,400 & 63,400 \\
\hline Farelo de soja & 22,100 & 25,300 & 27,230 \\
\hline Soro de leite & 20,580 & 10,504 & 0,000 \\
\hline Milho gelatinizado & 9,715 & 0,000 & 0,000 \\
\hline Açúcar & 4,000 & 4,000 & 3,000 \\
\hline Células sanguíneas & 2,800 & 1,830 & 0,000 \\
\hline Fosfato bicálcico & 2,225 & 2,200 & 2,350 \\
\hline Óleo de soja & 1,650 & 1,900 & 2,200 \\
\hline L-Lisina $\mathrm{HCl}$ & 0,485 & 0,410 & 0,530 \\
\hline Calcário calcítico & 0,369 & 0,400 & 0,410 \\
\hline Óxido de zinco & 0,300 & 0,180 & 0,000 \\
\hline Sal & 0,300 & 0,350 & 0,350 \\
\hline DL-Metionina & 0,100 & 0,100 & 0,100 \\
\hline L-Triptofano & 0,040 & 0,025 & 0,030 \\
\hline Cloreto de colina & 0,040 & 0,040 & 0,050 \\
\hline Antioxidante & 0,030 & 0,030 & 0,000 \\
\hline L-Treonina & 0,010 & 0,005 & 0,024 \\
\hline Olaquindox & 0,006 & 0,006 & 0,006 \\
\hline Sulfato de cobre & 0,000 & 0,070 & 0,070 \\
\hline Mistura vitamínica $^{2}$ & 0,150 & 0,150 & 0,150 \\
\hline Mistura mineral $^{3}$ & 0,100 & 0,100 & 0,100 \\
\hline Total & 100,00 & 100,00 & 100,00 \\
\hline \multicolumn{4}{|l|}{ Valores calculados: } \\
\hline Energia metabolizável (kcal/kg) & 3264 & 3266 & 3262 \\
\hline Proteína bruta $(\%)$ & 18,97 & 19,06 & 18,02 \\
\hline Cálcio $(\%)$ & 0,84 & 0,81 & 0,80 \\
\hline Fósforo total (\%) & 0,67 & 0,64 & 0,64 \\
\hline Lisina $(\%)$ & 1,49 & 1,35 & 1,26 \\
\hline Metionina (\%) & 0,41 & 0,39 & 0,36 \\
\hline Triptofano (\%) & 0,26 & 0,24 & 0,23 \\
\hline Treonina $(\%)$ & 0,96 & 0,89 & 0,81 \\
\hline
\end{tabular}

${ }^{1}$ As silagens substituíram os milhos secos correspondentes nas rações, com base na mesma matéria seca.

${ }^{2}$ Mistura vitamínica $/ \mathrm{kg} /$ ração: vit.A=9.000UI, vit.D3=2250UI, vit.E=22,5mg, vit.K3=2,25mg, vit.B1=2,03mg, vit.B2=6mg, vit.B6=3mg, vit.B12=30mcg, ac. fólico $=0,9 \mathrm{mg}$, ác. pantotênico $=14,03$, niacina $=30 \mathrm{mg}$, biotina $=0,12 \mathrm{mg}$.

${ }^{3}$ Mistura mineral $/ \mathrm{kg} /$ ração: $\mathrm{Fe}=100 \mathrm{mg}, \mathrm{Cu}=10 \mathrm{mg}, \mathrm{Mn}=40 \mathrm{mg}, \mathrm{Zn}=100 \mathrm{mg}, \mathrm{Co}=1 \mathrm{mg}, \mathrm{I}=1,5 \mathrm{mg}$.

Os grãos de milho com teores normal ou elevado de óleo, após serem colhidos com 29,3\% e $30,9 \%$ de umidade, respectivamente, foram triturados em peneira de $6 \mathrm{~mm}$ e em seguida ensilados em tambores plásticos de 100 e 200 litros, enquanto o milho seco, por ocasião da confecção das rações, foi moído em peneira de $2 \mathrm{~mm}$. O consumo diário de ração e o ganho diário de peso foram calculados, respectivamente, com base na pesagem da ração fornecida diariamente e com base na pesagem dos animais nos dias $0,9,25$ e 31 .

Amostras do milho seco, comum ou com teor superior de óleo, assim como suas respectivas silagens, foram submetidas à análise de $\mathrm{pH}$. As análises de granulometria das silagens e dos milhos secos foram realizadas segundo a metodologia descrita por Zanotto e Bellaver (1996). 
O experimento de digestibilidade foi realizado em abril e maio de 2003, utilizando-se 20 leitões mestiços (Large White/Landrace), machos castrados, com peso inicial médio de $16,8 \mathrm{~kg}$ alojados em gaiolas metabólicas, semelhantes às descritas por Pekas (1968).

O delineamento experimental foi o de blocos ao acaso com cinco tratamentos e quatro repetições. O critério para a formação dos blocos foi o peso. O período experimental teve duração de 13 dias, sendo sete dias de adaptação dos animais às gaiolas e às rações experimentais, e seis dias de coleta. Os tratamentos foram: $\mathrm{T} 1=$ raçãoreferência (Tab. 2); T2= mistura com $70 \%$ de ração-referência e $30 \%$ de milho seco com teor normal de óleo; T3= mistura com $70 \%$ de raçãoreferência e $30 \%$ de silagem de grãos úmidos de milho com teor normal de óleo; T4= mistura com $70 \%$ de ração-referência e $30 \%$ de milho seco com teor elevado de óleo; T5= mistura com 70\% de ração-referência e $30 \%$ de silagem de grãos úmidos de milho com teor elevado de óleo. As silagens e o milho seco foram os mesmos usados no experimento de desempenho e substituíram a ração-referência com base na matéria seca. Os demais procedimentos foram realizados conforme Fialho et al. (1979).

Foram feitas análises da matéria seca, proteína bruta, extrato etéreo e energia bruta das fezes e do alimento. $\mathrm{Na}$ urina foi analisada a energia bruta.

Foi empregado o método de Matterson et al. (1965) para os cálculos dos valores dos coeficientes de digestibilidade aparente da matéria seca, proteína bruta e extrato etéreo e dos valores de energia digestível e energia metabolizável dos alimentos.

Os dados de desempenho e de digestibilidade foram submetidos à análise de variância utilizando-se o PROC GLM do SAS (User's...,
1998), considerando não significativas as diferenças quando $\mathrm{P}>0,06$.

Tabela 2. Composição percentual e valores determinados da ração-referência fornecida para os leitões no experimento de digestibilidade ${ }^{1}$

\begin{tabular}{lc}
\hline Ingrediente & 62,800 \\
Milho moído & 27,500 \\
Farelo de soja & 3,000 \\
Açúcar & 2,606 \\
Óleo de soja & 2,350 \\
Fosfato bicálcico & 0,530 \\
L-Lisina HCl & 0,410 \\
Calcário calcítico & 0,350 \\
Sal & 0,100 \\
DL-Metionina & 0,050 \\
Cloreto de colina & 0,030 \\
L-Triptofano & 0,024 \\
L-Treonina & 0,150 \\
Mistura vitamínica & 0,100 \\
Mistura mineral & \\
\hline Total & 100,00 \\
\hline Valores determinados: & \\
Matéria seca $(\%)$ & 89,19 \\
Proteína bruta $(\%)^{4}$ & 19,38 \\
Extrato etéreo $(\%)^{4}$ & 5,58 \\
\hline
\end{tabular}

${ }^{\mathrm{T}}$ As silagens e os milhos secos correspondentes substituíram a ração referência, com base na mesma matéria seca.

${ }^{2}$ Mistura vitamínica/ $\mathrm{kg} /$ ração: vit. $\mathrm{A}=9.000 \mathrm{UI}$, vit.D3=2250UI, vit.E=22,5mg, vit.K3=2,25mg, vit.B1=2,03mg, vit.B2=6mg, vit.B6 $=3 \mathrm{mg}$, vit.B12 $=30 \mathrm{mcg}$, ac. fólico $=0,9 \mathrm{mg}$, ác. pantotênico $=14,03$, niacina $=30 \mathrm{mg}$, biotina $=0,12 \mathrm{mg}$.

${ }^{3}$ Mistura mineral $/ \mathrm{kg} / \mathrm{ração:} \mathrm{Fe}=100 \mathrm{mg}, \mathrm{Cu}=10 \mathrm{mg}, \mathrm{Mn}=40 \mathrm{mg}$, $\mathrm{Zn}=100 \mathrm{mg}, \mathrm{Co}=1 \mathrm{mg}, \mathrm{I}=1,5 \mathrm{mg}$.

${ }^{4}$ Valores expressos na matéria natural.

\section{RESULTADOS E DISCUSSÃO}

A composição bromatológica, os valores de $\mathrm{pH}$ e de diâmetro geométrico médio das partículas dos milhos secos moídos e das silagens são apresentados na Tab. 3. Na Tab. 4 encontram-se os resultados de desempenho dos leitões na primeira fase e durante todo período experimental.

Tabela 3. Composição bromatológica, valores de $\mathrm{pH}$ e de diâmetro geométrico médio (DGM) das partículas das silagens e dos milhos secos moídos

\begin{tabular}{lccccc}
\multicolumn{1}{c}{ Tipo de milho } & MS (\%) & PB (\%) & EE $(\%)^{1}$ & pH & DGM $(\mu \mathrm{m})$ \\
\hline Seco com teor normal de óleo & 87,91 & 11,09 & 4,30 & 5,99 & 600,73 \\
Seco com teor superior de óleo & 87,72 & 11,71 & 5,66 & 6,00 & 558,78 \\
Silagem com teor normal de óleo & 66,76 & 12,47 & 5,60 & 3,86 & 1275,20 \\
Silagem com teor superior de óleo & 66,95 & 12,30 & 5,53 & 4,03 & 1318,50 \\
\hline
\end{tabular}

${ }^{1}$ Valores expressos na matéria seca. $\mathrm{MS}=$ matéria seca, $\mathrm{PB}=$ proteína bruta, $\mathrm{EE}=$ extrato etéreo. 
Tabela 4. Médias de consumo de ração diário (CRD), ganho de peso diário (GPD) e conversão alimentar (CA) dos leitões na primeira fase ( 0 a 9 dias $)$ e durante todo o período experimental ( 0 a 31 dias $)^{1}$

\begin{tabular}{|c|c|c|c|c|c|c|c|}
\hline \multirow[b]{2}{*}{$\begin{array}{l}\text { Método de } \\
\text { conservação }\end{array}$} & \multirow[b]{2}{*}{$\begin{array}{l}\text { Teor de } \\
\text { óleo }\end{array}$} & \multicolumn{2}{|c|}{$\operatorname{CRD}(\mathrm{g})^{2}$} & \multicolumn{2}{|c|}{ GPD (g) } & \multicolumn{2}{|c|}{ CA } \\
\hline & & $\begin{array}{l}0-9 \\
\text { dias }\end{array}$ & $\begin{array}{c}0-31 \\
\text { dias }\end{array}$ & $\begin{array}{l}0-9 \\
\text { dias }\end{array}$ & $\begin{array}{c}0-31 \\
\text { dias }\end{array}$ & $\begin{array}{l}0-9 \\
\text { dias }\end{array}$ & $\begin{array}{c}0-31 \\
\text { dias }\end{array}$ \\
\hline \multirow{2}{*}{ Seco } & Elevado & 493 & 1000 & 412 & 576 & 1,20 & 1,74 \\
\hline & Normal & 470 & 907 & 367 & 530 & 1,28 & 1,71 \\
\hline \multirow{2}{*}{ Silagem } & Elevado & 399 & 919 & 353 & 591 & 1,13 & 1,55 \\
\hline & Normal & 419 & 956 & 348 & 594 & 1,20 & 1,61 \\
\hline $\begin{array}{l}\text { Método de } \\
\text { conservação }\end{array}$ & $\begin{array}{l}\text { Teor de } \\
\text { óleo }\end{array}$ & $\begin{array}{l}0-9 \\
\text { dias }\end{array}$ & $\begin{array}{c}0-31 \\
\text { dias }\end{array}$ & $\begin{array}{l}0-9 \\
\text { dias }\end{array}$ & $\begin{array}{c}0-31 \\
\text { dias }\end{array}$ & $\begin{array}{l}0-9 \\
\text { dias }\end{array}$ & $\begin{array}{c}0-31 \\
\text { dias }\end{array}$ \\
\hline Silagem & & 409 & 938 & 351 & 593 & $1,17 \mathrm{~b}$ & $1,58 b$ \\
\hline Seco & & 482 & 954 & 390 & 553 & $1,24 \mathrm{a}$ & $1,73 \mathrm{a}$ \\
\hline \multirow[t]{3}{*}{ Teor de óleo } & & & & & & & \\
\hline & Elevado & 446 & 960 & 383 & 584 & $1,16 \mathrm{~B}$ & 1,64 \\
\hline & Normal & 445 & 932 & 358 & 562 & $1,24 \mathrm{~A}$ & 1,66 \\
\hline $\begin{array}{l}\text { Método de } \\
\text { conservação }\end{array}$ & & $\begin{array}{l}0-9 \\
\text { dias }\end{array}$ & $\begin{array}{c}0-31 \\
\text { dias }\end{array}$ & $\begin{array}{l}0-9 \\
\text { dias }\end{array}$ & $\begin{array}{r}0-31 \\
\text { dias }\end{array}$ & $\begin{array}{l}0-9 \\
\text { dias }\end{array}$ & $\begin{array}{r}0-31 \\
\text { dias }\end{array}$ \\
\hline $\begin{array}{l}\mathrm{X} \\
\text { teor de óleo }\end{array}$ & & NS & NS & NS & NS & NS & NS \\
\hline CV (\%) & & 24,25 & 13,14 & 23,59 & 9,51 & 5,96 & 4,55 \\
\hline
\end{tabular}

${ }^{1}$ Médias nas colunas com letras distintas minúsculas para o fator método de conservação e maiúscula para fator teor de óleo diferem pelo teste $\mathrm{F}(\mathrm{P}<0,06)$.

${ }^{2}$ Valores corrigidos para a mesma base de matéria seca do milho seco correspondente (milho com teor normal de óleo $=87,91 \%$ de MS e milho com teor superior de óleo $=87,72 \%$ de MS).

$\mathrm{NS}=$ não significativo, $\mathrm{CV}=$ coeficiente de variação.

A composição de matéria seca, proteína bruta e extrato etéreo dos milhos secos e das silagens foram semelhantes às descritas pela Embrapa (Tabela...,1991). Quanto ao $\mathrm{pH}$ das silagens, os valores podem ser considerados adequados e caracterizam produtos de boa qualidade (Shaver, 2000). As médias de diâmetro geométrico médio (DGM) das partículas de milho seco para suínos estão dentro do intervalo recomendado por Zardo e Lima (1999), que é de 500 a $650 \mu \mathrm{m}$, enquanto que para as silagens, os valores determinados foram semelhantes àqueles obtidos por Lopes et al. (2001a,b).

Não houve efeito da interação método de processamento $\times$ teor de óleo sobre as variáveis estudadas. Os tratamentos não influenciaram o consumo diário de ração e ganho diário de peso em nenhum dos períodos avaliados. Resultados similares foram encontrados por Engelke et al. (1984), ao testarem silagem de grãos úmidos de milho para suínos em crescimento e terminação. Entretanto, Silva et al. (2003), ao estudarem silagem de grãos úmidos de milho com médio teor de óleo, observaram aumento no consumo diário de ração e ganho diário de peso de suínos em terminação, mas nenhum efeito foi encontrado durante a fase de crescimento.

Os leitões alimentados com silagem apresentaram melhor conversão alimentar na primeira fase $(\mathrm{P}<0,06)$ e em todo o período experimental $(\mathrm{P}<0,01)$, concordando com os resultados obtidos por Lopes et al. (2001a,b) e Tse et al. (2004).

De acordo com Lopes et al. (2002), o processo de ensilagem melhora o valor nutricional do milho, provavelmente em função das alterações estruturais que ocorrem no interior do endosperma dos grãos, como o rompimento da matriz protéica que envolve os grânulos de 
amido e as alterações nos próprios grânulos. Além disso, os melhores resultados da silagem também podem estar relacionados ao seu menor valor de $\mathrm{pH}$, comparado ao milho seco. Segundo Berto et al. (2001), e Sartori et al. (2002) a diminuição do $\mathrm{pH}$ pode determinar efeitos positivos, como maior ativação da pepsina, menor taxa de esvaziamento estomacal e inibição da proliferação de microrganismos.

O uso do milho com teor elevado de óleo melhorou a conversão alimentar $(\mathrm{P}<0,01)$ dos leitões na primeira fase do experimento, mas não influenciou o ganho de peso diário. Resultados semelhantes para conversão alimentar foram observados por Adams e Jensen (1987). Segundo Nordstrom et al. (1972), o conteúdo maior de óleo maximiza a eficiência alimentar dos suínos. Adeola e Bajjalieh (1997) observaram, apenas, melhora de $9 \%$ no ganho de peso de leitões alimentados com uma variedade de milho altoóleo em relação ao milho comum e sugere que a ausência de resultado para ganho de peso pode estar relacionada à limitada capacidade de ingestão de leitões jovens.

No período total não se verificou efeito do teor de óleo do milho sobre nenhuma das características de desempenho, o que pode ser devido à capacidade restrita, de leitões em fase de creche, na utilização de óleo suplementar (O’Quinn et al., 2000).

Os valores dos coeficientes de digestibilidade aparente da matéria seca, da proteína bruta e do extrato etéreo e os valores de energia digestível e metabolizável em função do método de conservação e do teor de óleo dos grãos de milho são mostrados na Tab. 5.

Tabela 5. Valores médios dos coeficientes de digestibilidade aparente da matéria seca (CDAMS), proteína bruta (CDAPB), extrato etéreo (CDAEE), dos teores de energia digestível (ED) e metabolizável (EM), em função do método de conservação e do teor de óleo dos grãos de milho ${ }^{1}$

\begin{tabular}{|c|c|c|c|c|c|c|}
\hline $\begin{array}{l}\text { Método de } \\
\text { conservação }\end{array}$ & $\begin{array}{l}\text { Teor de } \\
\text { óleo }\end{array}$ & $\begin{array}{c}\text { CDAMS } \\
(\%)\end{array}$ & $\begin{array}{c}\text { CDAPB } \\
(\%)\end{array}$ & $\begin{array}{c}\text { CDAEE } \\
(\%)\end{array}$ & $\begin{array}{c}\text { ED } \\
(\mathrm{kcal} / \mathrm{kgMS})\end{array}$ & $\begin{array}{c}\text { EM } \\
\text { (kcal/kgMS) }\end{array}$ \\
\hline \multirow{2}{*}{ Seco } & Superior & 87,02 & 76,26 & 76,42 & 3753 & 3672 \\
\hline & Normal & 86,65 & 75,43 & 75,57 & 3774 & 3682 \\
\hline & Superior & 85,11 & 73,65 & 77,88 & 4157 & 4061 \\
\hline $\begin{array}{l}\text { Métodos de } \\
\text { conservação }\end{array}$ & Normal & 84,60 & 73,30 & 75,18 & 4104 & 3935 \\
\hline Seco & & 86,84 & 75,85 & 76,00 & $3764 a$ & $3677 \mathrm{a}$ \\
\hline Silagem & & 84,86 & 73,48 & 76,53 & $4131 \mathrm{~b}$ & $3998 b$ \\
\hline $\begin{array}{l}\text { Teor de óleo } \\
\text { Superior }\end{array}$ & & 86,07 & 74,96 & 77,15 & 3955 & 3867 \\
\hline Normal & & 85,63 & 74,37 & 75,38 & 3939 & 3809 \\
\hline $\begin{array}{l}\text { Método de } \\
\text { conservação } \\
\text { X } \\
\text { Teor de óleo }\end{array}$ & & NS & NS & NS & NS & NS \\
\hline CV (\%) & & 5,23 & 12,65 & 21,44 & 5,28 & 6,23 \\
\hline
\end{tabular}

Não houve efeito da interação método de processamento $\mathrm{x}$ teor de óleo sobre variáveis estudadas. Quanto ao método de conservação e aos teores de óleo dos grãos de milho, não se observaram efeitos nos coeficientes de digestibilidade aparente da matéria seca, da proteína bruta e do extrato etéreo. Adeola e Bajjalieh (1997) também não constataram 
diferenças nos coeficientes de digestibilidade quando compararam uma variedade de milho comum $(4,8 \%$ de extrato etéreo na MS) e três variedades de milho alto-óleo $(11,0 \%, 6,6 \%$ e $6,2 \%$ de extrato etéreo na MS). Yin et al. (2002) também não observaram diferença significativa para digestibilidade fecal aparente da matéria seca, que variou entre 86 e $87 \%$, mas encontraram diferença significativa $(\mathrm{P}<0,05)$ para a digestibilidade fecal aparente do extrato etéreo entre as variedades de milho comum e a variedade de milho alto-óleo $(3,1 \%, 3,6 \%$ e $6,9 \%$ de extrato etéreo na matéria seca), atribuída ao menor conteúdo de óleo nos milhos comuns, resultando numa contribuição relativamente maior da fração endógena no extrato etéreo excretado nas fezes e, conseqüentemente, menores valores de coeficiente de digestibilidade.

O coeficiente de digestibilidade médio do extrato etéreo dos milhos avaliados foi de $76,3 \%$, valor semelhante ao obtido (77\%) por Adams e Jensen (1984) e segundo esses autores existe boa utilização do extrato etéreo contido no milho com alto teor de óleo, porém, menor que a do óleo extraído do milho (coeficientes de digestibilidade de $77 \%$ e de $85 \%$, respectivamente).

A energia digestível e a metabolizável foram influenciadas pelo método de conservação, sendo que a ensilagem proporcionou melhor aproveitamento da energia $(\mathrm{P}<0,05)$, independentemente do teor de óleo presente nos grãos, diferente dos resultados obtidos por Adeola e Bajjalieh (1997) que encontraram diferenças $(\mathrm{P}<0,05)$ para os valores de energia digestível e metabolizável entre as variedades de milho seco comum e de alto teor de óleo, provavelmente, em função da grande diferença ( 3,15 pontos percentuais) no teor de extrato etéreo entre as variedades estudadas.

O fato de não ter sido encontrada diferença significativa nos coeficientes de digestibilidade pode ser atribuído à menor diferença no teor de extrato etéreo entre os grãos de milho estudados $(4,3 \%$ e $5,7 \%$ na $\mathrm{MS})$.

Os maiores valores de energia digestível e metabolizável da silagem, provavelmente estejam relacionados às modificações dos grânulos de amido durante a ensilagem (Lopes et al., 2002) facilitando o ataque enzimático durante a digestão. Para Lima et al. (1999), a fermentação anaeróbica na silagem de grãos úmidos de milho propicia um produto com alto valor energético para os suínos, pois encontraram valores de energia digestível de 4070 a $4123 \mathrm{kcal} / \mathrm{kg}$ de matéria seca e energia metabolizável de 3929 a $3990 \mathrm{kcal} / \mathrm{kg}$ de matéria seca, semelhantes aos valores de energia do presente experimento.

\section{CONCLUSÕES}

O processo de ensilagem melhora o valor nutricional do milho, em razão da maior disponibilidade de energia. O milho com teor superior de óleo pode ser utilizado mais eficientemente pelos leitões, especialmente nas duas primeiras semanas após o desmame.

\section{REFERÊNCIAS BIBLIOGRÁFICAS}

ADAMS, K.L.; JENSEN, A.H. Comparative utilization of in seed fats and the respective extracted fats by the young pig. J. Anim. Sci., v.59, p.1557-1566, 1984.

ADAMS, K.L.; JENSEN, A.H. High-fat-maize in diets for pigs and sows. Anim. Feed Sci. Technol., v.17, p.201-212, 1987.

ADEOLA, O.; BAJJALIEH, N.L. Energy concentration of high-oil corn varieties for pigs. $J$. Anim. Sci., v.75, p.430-436, 1997

BERTO, D.A.; LOPES, A.B.F.C.; COSTA, C. Silagem de grãos úmidos para suínos. In: SIMPÓSIO SOBRE MANEJO E NUTRIÇÃO DE AVES E SUÍNOS E TECNOLOGIA DA PRODUÇÃO DE RAÇÕES, 2001, Campinas. Anais... Campinas: CBNA, 2001. p.203-218.

BOWERS, K.A.; KENDALL, D.C.; RICHERT, B.T. Evaluating high oil corn and normal corn on an equal substitution basis for grow-finish pigs. Swine day, 2000. Disponível em: $<$ http://www.ansc.purdue.edu/swine/swineday/sday 00/6.pdf>. Acessado em 05 fev. 2004.

DUDUK, V. High moisture corn for fattened pigs. G. Agric., v.1, p.71-78, 1988.

ENGELKE, G.L.; JURGENS, M.H.; SPEER, V.C. Performance of growing-finishing swine fed highmoisture or artificially dried corn in complete and free-choice diets. J. Anim. Sci., v.58, p.1307-1312, 1984. 
FIALHO, E.T.; ROSTAGNO, H.S.; FONSECA, J.B. et al. Efeito do peso vivo sobre o balanço energético e protéico de rações à base de milho e de sorgo com diferentes conteúdos de tanino para suínos. Rev. Bras. Zootec., v.8, p.386-397, 1979.

LIMA, G.J.M.M.; SOUZA, O.W.; BELLAVER, C. et al. Composição química e valor energético de silagem de grãos úmidos de milho para suínos. Concórdia: Embrapa Suínos e Aves, 1999. 2p. (Comunicado Técnico, 240).

LOPES, A.B.R.C.; BERTO, D.A.; COSTA, C. et al. Silagem de grãos úmidos de milho para suínos na fase inicial dos 8 aos 30kg. Bol. Ind. Anim., v.58, p.181-190, 2001a.

LOPES, A.B.R.C.; BERTO, D.A.; COSTA, C. et al. Silagem de grãos úmidos de milho para suínos nas fases de crescimento e terminação. Bol. Ind. Anim. v.58, p.191-200, 2001b.

LOPES, A.B.R.C.; LEONEL, M.; CEREDA, M.P. et al. Efeito do processo de ensilagem de grãos úmidos de milho nas características do amido. Braz. J. Food Technol., v.5, p.177-181, 2002.

MATTERSON, L.D.; POTTER, L.M.; STUTZ, M.W. et al. The metabolizable energy of feed ingredients for chickens. Res. Report, v.7, p.11-14, 1965.

NORDSTROM, J.W.; BEHRENDS, B.R.; MEADE, R.J. et al. Effects of feeding high-oil corn to growing-finishing swine. J. Anim. Sci., v.35, p.357-361, 1972 .

NUTRIENT requirements of swine. 20.ed. Washington: NRC, 1998. 189p.

O'QUINN, P.R.; NELSSEN, J.L.; GOODBAND, R.D. et al. Nutritional value of a genetically improved high-lysine, high-oil corn for young pigs. J. Anim. Sci., v.78, p.2144 - 2149, 2000.

PEKAS, J.C. Versatile swine laboratory apparatus for physiologic and metabolic studies. J. Anim. Sci., v.27, p.1301-1306, 1968.

SARTORI, J.R.; COSTA, C.; PEZZATO, A.C. et al. Silagem de grãos úmidos de milho na alimentação de frangos de corte. Pesq. Agropec. Bras., v.37, p.1009-1015, 2002.

SHAVER, R.D. Colheita e armazenamento de milho para a produção de silagem de alta qualidade para vacas leiteiras. In: NOVOS ENFOQUES NA PRODUÇÃO E REPRODUÇÀO DE BOVINOS,
4., 2000. Passos, Anais... Passos: UNESP, 2000. p.63-66.

SILVA, L.P.G. Efeitos da utilização do milho com alto teor de óleo sobre o desempenho $e$ características das carcaças dos suínos. 1997. 141f. Tese (Doutorado) - Faculdade de Ciências Agrárias e Veterinárias, Universidade Estadual Paulista, Jaboticabal, SP.

SILVA, M.A.A.; FURLAN, A.C.; MOREIRA, I. et al. Desempenho de suínos em crescimento/terminação alimentados com milho de médio teor de óleo na forma de milho seco e silagens. In: CONGRESSO BRASILEIRO DE VETERINÁRIOS ESPECIALISTAS EM SUÍNOS, 11., 2003. Goiânia, Anais... Goiânia: ABRAVES, 2003. p.337-338.

SPURLOCK, M.E.; FRANK, G.R.; WILLIS, G.M. et al. Effect of dietary energy source and immunological challenge on growth performance and immunological variables in growing pigs. $J$. Anim. Sci., v.75, p.720-726, 1997.

TABELA de composição química e valores energéticos para suínos e aves. 3.ed. Concórdia: Embrapa Suínos e Aves, 1991. 97p. (Doc. 19).

TSE, M.L.P.; BERTO, D.A.; TÓFOLI, C.A. et al. Grãos úmidos de milho ensilados com diferentes granulometrias sobre o desempenho de leitões na fase de creche. In: REUNIÃO ANUAL DA SOCIEDADE BRASILEIRA DE ZOOTECNIA, 41., 2004. Campo Grande. Anais... Campo Grande: SBZ, 2004. CD-ROM.

USER'S guide: statistics. Version 6.12. Cary, NC: SAS Institute, 1998

YIN, Y.L.; GURUNG, NAR K.; JEAUROUND, E.A. et al. Digestible energy and amino acid contents in Canadian varieties of sorghum, pearl millet, high-oil corn, high-oil-high-protein corn and regular corn samples for growing pigs. Can. J. Anim. Sci., v.82, p.385-391, 2002.

ZANOTTO, L.D.; BELLAVER, C. Método de determinação de granulometria de ingredientes para uso em rações de suínos e aves. Concórdia: Embrapa Suínos e Aves, 1996. p.1-5 (Comunicado Técnico, 215).

ZARDO, A.O.; LIMA, G.J.M.M. Alimentos para suínos. Concórdia: Embrapa Suínos e Aves, 1999. (Boletim Informativo, 12). 